\title{
Aerobic or Motor Skills Exercise? What about their Impact on Academic Achievements?
}

\author{
Ingegerd Ericsson* \\ Associate professor Sport Sciences, Malmö University, Sweden
}

*Corresponding author: Ingegerd Ericsson, Associate professor Sport Sciences, Malmö University, Nordenskiöldsgatan 10, S-205

06 Malmö, Sweden

\begin{tabular}{|c|c|}
\hline ARTICLE INFO & ABSTRACT \\
\hline Received: 幽 January 16, 2020 & Citation: Ingegerd Ericsson. Aerobic or Motor Skills Exercise? What about their Impact \\
\hline Published: 蔧 January 22, 2020 & on Academic Achievements?. Biomed J Sci \& Tech Res 24(5)-2020. BJSTR. MS.ID.004110. \\
\hline
\end{tabular}

\section{Short Communication}

Although strong evidence for positive effects on mathematics was reported in a review by Singh et al. [1] there is currently inconclusive evidence for the beneficial effects of physical activity (PA) on academic performance in children. Relationship between physical fitness and academic achievement is frequently reported. Children who are more physically fit tend to have higher cognitive functions and academic achievements; especially aerobic endurance seems to be linked to academic achievement. However, not all forms of exercise influence cognition equally and results from interventions with aerobic exercise are not very promising. In fact, aerobic exercise interventions (e.g. running or walking) and resistance training show the least benefit for improving executive functioning (EF) of all interventions, according to Diamond et al. [2]. Measures of EF (inhibitory control, working memory, and cognitive flexibility) are often used as indicators of cognition and learning. An intervention among adolescents consisted of increased PA 20min/day with focus on intense aerobic exercise and low cognitive demands. No effects were found on any EF. Sjöwall et al. [3] conclude that aerobic exercise with low cognitive load does not produce improvements in EF.

The impact of physical fitness on academic achievement may have been overestimated in many studies when other important factors have not been included. Recommendations for PA thus focus on the quantitative aspects and health-related components of physical fitness. The importance of motor skill acquisition (e.g. balance and coordination) early in life is often overlooked, which may limit qualitative aspects of interventions, such as motor skill development, socialization and enjoyment of exercise. Oberer et al. [4] found that early physical fitness had only an indirect effect on later scholastic performance and state that visual-motor coordination is an overlooked indicator of school readiness. Thus, it may not be the change in cardiovascular fitness that determines improvements in EF. Could it be improvements in motor skills, rather than changes in fitness, that improve EF and learning? Neuropsychological studies report that the same brain areas are activated during motor and EF tasks Diamond [5]. In a consensus conference 24 researchers from different research areas conclude that mastery of fundamental motor skills is beneficial to cognition and scholastic performance in children and youth Bangsbo et al. [6].

Learning new motor skills can be demanding, both coordinately as well as cognitively and it seems to be one way to improve cognitive functions, especially EF. Oberer et al. [4] found that visualmotor coordination was a stronger predictor for later academic achievement than physical fitness, suggesting that visual-motor coordination is of particular importance in the beginning of formal schooling when learning to write is not yet automatized. Children with better visual-motor coordination are thus at an advantage compared to children with less well-developed motor coordination. Intervention programs over several weeks that include cognitively challenging PA (i.e. exercises that require complex, controlled motor skills) seem to be more effective in improving EF and cognitive performance than aerobic exercise Koutsandréou et al. [7,8]. A theoretical explanation is the cognitive stimulation hypothesis, which assumes that coordinative demanding PA (e.g. learning 
new motor skills, sports or coordinative skills) not only increases physical fitness, but also enhances higher-order cognitive control, i.e. EF Tomporowski et al. [9]. Although motor skills were found to be a stronger predictor of academic achievement than aerobic fitness de Bruijn et al. [10], the authors conclude that children's academic achievement benefits most from PA that include both aerobic fitness and gross motor skills.

Koutsandréou et al. [7] examined the impact of aerobic compared to motor skills exercise on primary school children's working memory. Students in a control group had assisted homework sessions. Working memory performance benefited from both the aerobic and motor exercise programs, but not from the control condition. The increase in working memory was significantly larger for children in the motor exercise compared to the aerobic exercise group. Special motor demanding interventions seems to be a beneficial strategy to improve working memory in preadolescent children. Schmidt et al. [11] also recommend physical activities that are cognitively and coordinately demanding. In a systematic review by Macdonald et al. [12] statistically significant effects of motor skill interventions on academic performance compared to control groups were found in all four examined studies. In the Swedish Bunkeflo project Ericsson et al. [13] studied long-term effects on motor skills and scholastic performance of daily physical education (PE) and adapted MUGI motor skills support (Figure 1) for children in need of it. In the intervention group significant improvements were found in reading, writing and mathematics, and $96 \%$ of the students compared to $89 \%$ in the control group qualified for upper secondary school. The intervention was an effective way to improve not only motor skills but also academic achievements. Health-economic analyses show that daily PE and MUGI motor skills exercise would give society gains (reduced morbidity costs and productivity gains) of SEK 38,000 (Euro 4,130) per student ten years after leaving school Gerdtham et al. [14].

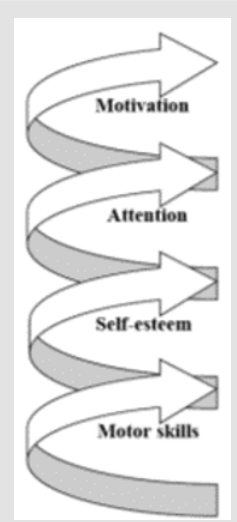

Figure 1: The Motor skills Development as Ground for Learning (MUGI) model for understanding the relationship between motor skills and learning: Improvements and automatization of fundamental motor skills lead to increased self-efficacy and physical self-esteem, which give better prerequisites for attention and comfort in school, which lead to increased motivation to learn new things.
Diamond et al. [8] report that school programs have had much better results for improving inhibitory control than any other approach. However, not all school programs show positive results. In Scandinavia it has become quite popular to use pulse-raising exercise in the classroom during regular lessons. Seven minutes of pulse-raising exercise at the beginning of each mathematic lesson showed no improvements in mathematics in the intervention group compared to a control group Balan et al. [15]. Another intervention study examined the effect of Movement Integrated into Teaching. There were no effects on 13-15 years-old students' reading and math scores after 12 weeks Løgstrup Ottesen et al. [16]. A meta-analysis by Álvarez-Bueno et al. [17] gave the same result that classroom-based PA did not have a positive impact on children's cognition. Moderate levels of PA may have the greatest benefit and high levels of PA might impair cognitive performance. PA immediately prior to a learning session should not be too intense since high stress or fatigue may blunt the beneficial effect Bangsbo et al. [6]. Preadolescent children had daily intense aerobic exercise in school, aimed at increasing cardiovascular fitness. The results after two years showed that longtime high intensity PA did not lead to any improvement in working memory or mathematics Sjöwall et al. [18]. Unexpectedly, a significant increase in self-rated stress was detected in the intervention group, especially among girls.

The meta-analysis by Álvarez-Bueno et al. [17] showed that especially PE can improve several aspects of academic achievement, e.g. mathematics and reading-related skills. In interventions developed by trained PE teachers, the benefits were greater. Dalziella et al. [19] found lasting cognitive and coordination improvements after a PE intervention including fundamental locomotor skills (crawling, creeping, marching and skipping). These results are in line with the findings in the Bunkeflo project Ericsson et al. [13]. In addition, research shows that children with a competent level of motor skill performance are more likely to be and stay physically active after leaving school. A problem in many studies is that researchers tend to study only the intensity of PA. It may not be the level or intensity of aerobic exercise that needs to be investigated. In future studies researchers need to focus on the quality of physical activities and different school programs; what kind of exercise is important for children's learning and well-being in school? There is a need for more controlled studies that investigate the impact of different physical activities, especially the differences between effects of aerobic exercise compared to motor skills exercise on students' academic achievements.

\section{References}

1. Singh AS, Saliasi E, Van den Berg V, Uijtdewilligen L, De Groot RH, et al. (2018) Effects of physical activity interventions on cognitive and academic performance in children and adolescents: A novel combination of a systematic review and recommendations from an expert panel. British Journal of Sports Medicine 53(10): 640-647.

2. Diamond A, Ling D (2018) Aerobic-Exercise and resistance-training interventions have been among the least effective ways to improve executive functions of any method tried thus far. Developmental Cognitive Neuroscience 37: 100572. 
3. Sjöwall D, Thorell LB, Mandic M, Westerståhl M (2019) No effects of a long-term physical activity intervention on executive functioning among adolescents. SAGE Open Medicine 7: 1-7.

4. Oberer N, Gashaj V, Roebers CM (2018) Executive functions visual-motor coordination physical fitness and academic achievement: Longitudinal relations in typically developing children. Human Movement Science 58: 69-79.

5. Diamond A (2000) Close interrelation of motor development and cognitive development and of the cerebellum and prefrontal cortex. Child Development 71(1): 44-56.

6. Bangsbo J, Krustrup P, Duda J, Hillman C, Andersen L, et al. (2016) The Copenhagen Consensus Conference 2016 - Children, Youth and Physical Activity in Schools and during Leisure Time 50(19).

7. Koutsandréou F, Wegner M, Niemann C, Budde H (2016) Effects of Motor versus Cardiovascular Exercise Training on Children's Working Memory. Medicine and Science in Sports and Exercise 48(6): 1144-1152.

8. De Greeff JW, Bosker RJ, Oosterlaan J, Visscher C, Hartman E (2018) Effects of physical activity on executive functions attention and academic performance in preadolescent children: a meta-analysis. J Sci Med Sport 21(5): 501-507.

9. Tomporowski PD, Davis CL, Miller PH, Naglieri JA (2008) Exercise and children's intelligence cognition and academic achievement. Educational Psychology Review 20(2): 111-131.

10. De Bruijn AG, Kostons DD, Van der Fels IM, Visscher C, Oosterlaan J, et al. (2019) Importance of aerobic fitness and fundamental motor skills for academic achievement. Psychology of Sport \& Exercise 43: 200-210.

11. Schmidt M, Egger F, Benzing V, Jäger K, Conzelmann A, et al. (2017) Disentangling the relationship between children's motor ability executive function and academic achievement. PLoS ONE 12(8): 1-19.

\section{ISSN: 2574-1241}

DOI: $10.26717 / B J S T R .2020 .24 .004110$

Ingegerd Ericsson. Biomed J Sci \& Tech Res

CC This work is licensed under Creative

Submission Link: https://biomedres.us/submit-manuscript.php
12. Macdonald K, Milne N, Orr R, Pope R (2018) Relationships Between Motor Proficiency and Academic Performance in Mathematics and Reading in School-Aged Children and Adolescents: A Systematic Review. Int J Environ Res Public Health 15(8): pii: E1603.

13. Ericsson I, Karlsson M (2014) Motor Skills and School Performance in Children with Daily Physical Education in School - A Nine-Year Intervention Study. Scandinavian Journal of Medicine and Science in Sports 24(2): 273-278.

14. Gerdtham U, Ghatnekar O, Svensson M (2013) Health economics evaluations - basic data for the Commission for a Socially Sustainable Malmö. Malmö: Commission for a Socially Sustainable Malmö.

15. Balan A, Green J (2019) Effekten av fysisk aktivitet i matematikundervisningen, Forskning om undervisning och lärande 3(7): 6-27.

16. Løgstrup Ottesen C, Von Seelen J (2019) Physically Active Lessons in Secondary School, An Intervention Study. Idrottsforum.org.

17. Álvarez Bueno C, Pesce C, Cavero Redondo I, Sánchez López M, Martínez Hortelano J, et al. (2017) The Effect of Physical Activity Interventions on Children's Cognition and Metacognition: A Systematic Review and Meta-Analysis. J Am Acad Child Adolesc Psychiatry 56(9): 729-738.

18. Sjöwall D, Hertz M, Klingberg T (2017) No Long-Term Effect of Physical Activity Intervention on Working Memory or Arithmetic in Preadolescents. Front Psychol 8: 1342.

19. Dalziella A, Bootha JN, Boyleband J, Mutrieaa N (2019) Better Movers and Thinkers: An evaluation of how a novel approach to teaching physical education can impact children's physical activity coordination and cognition. British Educational Journal 45(3): 576-591.

$\begin{array}{ll}\text { BIOMEDICAL } & \text { Assets of Publishing with us } \\ \text { RESEARCHES } & \text { - Global archiving of articles } \\ \text { - Immediate, unrestricted online access } \\ \text { - Rigorous Peer Review Process } \\ \end{array}$

